\title{
Commentary \\ Recent translational research: stem cells as the roots of breast cancer \\ Chia-Cheng Chang
}

Department of Pediatrics and Human Development, Michigan State University, East Lansing, Michigan, USA

Corresponding author: Chia-Cheng Chang, cc.chang@ht.msu.edu

Published: 24 February 2006

This article is online at http://breast-cancer-research.com/content/8/1/103 (c) 2006 BioMed Central Ltd
Breast Cancer Research 2006, 8:103 (doi:10.1186/bcr1385)

breast tumorigenesis. Recently, several different human cancers, including breast cancer, were shown to contain tumor-initiating stem cells [9-11]. These cells are believed to sustain breast tumor growth and to be targets for cancer treatment. However, the role of these cells in breast tumor progression and the prevalence of these cells in clinical outcome are not yet clear [12].

\section{Common phenotypes of human breast epithelial stem cells and tumor cells}

Two types of normal human breast epithelial cells (HBECs) derived from reduction mammoplasty have been isolated and characterized [7]. Type I HBECs express estrogen receptor (ER)- $\alpha$ and luminal epithelial cell markers (i.e. epithelial membrane antigen and cytokeratin [CK]18). These cells also exhibit stem cell characteristics, including deficiency in GJIC [7], capacity for anchorage-independent growth (AIG) [13], ability to differentiate into basal (type II HBECs) and luminal (acini-forming) epithelial cells [7,13], expression of the embryonic stem cell marker Oct-4 [3], and the ability to form budding/ductal structures on Matrigel $[13,14]$. In contrast to type II HBECs, which have basal epithelial characteristics [7,13], type I HBECs share many common phenotypes with breast carcinoma cells such as MCF-7, including deficiency in GJIC and expression of ER- $\alpha$, epithelial membrane antigen, CK18, and Oct-4 [3,7,13-16].

In human breast cancer, two lines of observations have been cited as evidence in favor of the stem cell theory of carcinogenesis. First, pregnancy may reduce the risk of breast cancer possibly by inducing the differentiation of mammary gland and reducing the number of breast stem cells [5]. Second, in a Japanese study of the effects of atomic bomb detonation [6], evaluation of the radiation effect revealed that young women were more susceptible to radiation-induced breast cancer. Breast epithelial cells with stem cell features have been isolated $[7,8]$. Characterization of these cells provides more direct evidence for the stem cell hypothesis of

\section{Breast epithelial stem cells as major target cells for carcinogenesis}

Type I HBECs have been shown to be more susceptible to telomerase activation and immortalization following SV40 (simian virus 40) large T-antigen transfection [14]. These immortalized type I HBECs can then be converted to weakly tumorigenic and highly tumorigenic cells by $\mathrm{X}$-ray irradiation (the best known breast carcinogen) and c-erbB2/neu (a well known breast oncogene) [17]. Expression of Oct-4 [3] and

$\mathrm{AIG}=$ anchorage independent growth; $\mathrm{CK}=$ cytokeratin; $\mathrm{ER}=$ estrogen receptor; $\mathrm{GJIC}=$ gap junctional intercellular communication; $\mathrm{HBEC}=$ human breast epithelial cell. 
lack of expression of the protease inhibitor maspin [16] were identified in these cells at all stages of neoplastic transformation, providing strong evidence that type I HBECs are major target cells for carcinogenesis. It should be noted that, in contrast to type II HBECs, type I HBECs do not express three genes (connexin 26, $\alpha_{6}$ integrin, and maspin) that are considered to be tumor suppressor genes [18-20]. Furthermore, type I HBECs were capable of AIG at low and high frequencies before and after overcoming senescence, respectively $[7,13]$. In the literature many SV40 immortalized HBECs have been reported, but none of them was capable of AIG (for references, see the report by Kao and coworkers [7]). Many of the tumor phenotypes possessed by type I HBECs may contribute to the high susceptibility of these cells to neoplastic transformation.

A different approach following the isolation of neuronal stem cells as neurospheres [21] has been employed to isolate nonadherent mammospheres [8]. These mammosphere cells have been shown to differentiate along three mammary epithelial lineages (luminal, myoepithelial, and alveolar) in conditions that favor differentiation, and to clonally generate complex functional structures in three dimensional culture. The stem cell features of mammospheres also include Hoechst dye exclusion and expression of some genes that are involved in stem cell/progenitor cell-specific functions [4]. Unlike type I HBECs, mammosphere cells have not been shown to express ER- $\alpha$ or Oct-4, and to be more susceptible to neoplastic transformation.

\section{Two breast tumor types phenotypically corresponding to two normal HBEC types}

Immunohistochemical and mRNA expression profiling studies of large breast cancer cohorts have reproducibly identified a subset (about 15\%) of tumors expressing markers of the basal layer of the mammary gland [22]. These tumors are invariably ER negative with high p53 mutations, rarely contain amplified HER2, and are generally high grade/poorly differentiated and associated with poor prognosis. The phenotypes of these cells are similar to those of type II HBECs, which express basal epithelial cell markers and are ER negative $[7,13,15]$. In contrast, the majority of human breast cancers are ER positive, express luminal cytokeratins (CK8, CK18, and CK19) and harbor a low frequency of p53 mutation [22]. The phenotypes of these tumors are clearly similar to those of the type I HBECs, which express CK18, CK19 and ER- $\alpha$, and can be neoplastically transformed by HER2/neu oncogene $[13,17]$. The corresponding phenotypes of these two types of breast tumors with two types of normal breast epithelial cells suggest two different target cells for breast carcinogenesis, namely type I and early type II HBECs, which are highly proliferative and could be precursors for myoepithelial cells. However, common mammary stem or progenitor cells could give rise to two types of breast tumors, as shown by the coexistence of luminal and myoepithelial cells in mouse mammary tumors induced by
Wnt signaling [23] and the expression of different lineagespecific markers by cultured breast tumor mammospheres under differentiating conditions [24]. It is possible that tumor stem cell differentiation may involve a wholesale switch in gene expression, similar to the differentiation of type I HBECs [7].

\section{The origin of breast tumor stem cells}

In recent years cancer-initiating stem cells have been reported for human leukemia, myeloma, and brain and breast tumors. In most cases, the markers for cancer stem cells are also markers for normal stem cells in the same tissue (i.e. CD34 ${ }^{+} / \mathrm{CD}_{38}{ }^{-}$for leukemia stem cells and hematopoietic stem cells [25], and CD133+ and nestin ${ }^{+}$for brain tumor stem cells and normal neural stem cells [10]), suggesting that the initiating target cells are stem cells and not the committed progenitor cells. The breast cancer-initiating cells have been identified as CD44+/CD24//low Lineage ${ }^{-}$[11] and have not been cultured as adherent cells. These markers were not found in adherent type I HBEC with stem cell characteristics. In fact, the immortal and tumorigenic type I HBECs were CD44-/CD24+ [16]. The discrepancy could be due to the selection of $\mathrm{CD} 44^{+} / \mathrm{CD} 24^{-/ \text {low }}$ cells, which are nonadherent, and the culture of type I HBECs as adherent cells, which would exclude CD44 ${ }^{+} / \mathrm{CD} 24^{-}$cells. Because a subpopulation of type I HBECs was capable of AIG [13], these cells could exhibit a CD44+/CD24- phenotype and give rise to the reported breast tumor stem cells.

In vitro propagation of tumor-initiating breast tumor cells has recently been reported [24]. These cells are CD44+/ CD24-/low and Oct-4+/connexin 43-; the latter are similar to type I HBECs [3,13]. On the other hand, although mammospheres can be formed by a subpopulation of breast epithelial cells and tumor cells. Some important breast tumor phenotypes such as ER- $\alpha$ and Oct-4 expression and deficiency in GJIC have not been demonstrated in normal mammospheres. The origin of breast cancer from mammosphere cells remains to be demonstrated. Identification and elucidation of the nature of target cells for breast carcinogenesis will help us to develop preventive, early detection, and therapeutic strategies for breast cancer.

\section{The role of $C D 44^{+} / \mathrm{CD}^{2} 4^{-/ \text {low }}$ cells in tumor progression and clinical outcome}

The in vitro culture of CD44+/CD24- tumor mammospheres was successful for a minority of breast tumor samples (three out of 16) [24]. This indicates either the absence of CD44 ${ }^{+} / \mathrm{CD} 4^{-}$in most breast tumors (13 out of 16 ) or a limitation of the culture method. In a clinical study, the CD44+/CD24-/low tumor cells were not found to increase in tumor progression from carcinoma in situ to carcinoma but may favor distant metastasis [12]. There was no significant correlation between the prevalence of CD44+/CD24-/low tumor cells and event-free or overall survival in breast cancer patients. These findings must be verified by further independent studies. 


\section{Conclusion}

There is substantial evidence in favor of the stem cell theory of breast carcinogenesis, based on the observation of phenotypes common to breast stem cells and tumor cells and on the demonstration that breast epithelial cells with stem cell features were more susceptible to neoplastic transformation. However, the origin of breast tumor stem cells remains unsettled. This may be resolved by identification of a subpopulation of type I HBECs that are nonadherent and with CD44+/CD24- expression and/or demonstration that the nonadherent mammosphere cells are target cells for neoplastic transformation. The reported lack of correlation between the prevalence of CD44+/CD24- cells and clinical outcomes requires examination in further studies.

\section{Competing interests}

CC holds US Patents 5650317, 5814511 and 6140119 which are related to this commentary.

\section{References}

1. Henahan D, Weinberg RA: The hallmarks of cancer. Cell 2000, 100:57-70.

2. Trosko JE, Chang CC, Upham BL, Tai MH: Ignored hallmarks of carcinogenesis: stem cells and cell-cell communication. Ann NY Acad Sci 2004, 1028:192-201.

3. Tai MH, Chang CC, Kiupel M, Webster JD, Olson LK, Trosko JE: Oct4 expression in adult human stem cells: evidence in support of the stem cell theory of carcinogenesis. Carcinogenesis 2005, 26:495-502.

4. Liu S, Dontu G, Wicha MS: Mammary stem cells, self-renewal pathways, and carcinogenesis. Breast Cancer Res 2005, 7:8695.

5. Russo $\mathrm{IH}$, Koszalka M, Russo J: Human chorionic gonadotropin and rat mammary cancer prevention. J Nat/ Cancer Inst 1990, 82:1286-1289.

6. Thompson DE, Mabuchi K, Ron E, Soda M, Tokunaga M, Ochikubo S, Sugimoto S, Ikeda T, Terasaki M, Preston DL: Cancer incidence in atomic bomb survivors. Part II: Solid tumors 1958-1987. Radiat Res 1994, Suppl:S17-S67.

7. Kao CY, Nomata K, Oakley CS, Welsch CW, Chang CC: Two types of normal human breast epithelial cells derived from reduction mammoplasty: phenotypic characterization and response to SV40 transfection. Carcinogenesis 1995, 16:531538.

8. Dontu G, Abdallah WM, Foley JM, Jackson KW, Clarke MF, Kawamura MJ, Wicha MS: In vitro propagation and transcriptional profiling of human mammary stem/progenitor cells. Genes Dev 2003, 17:1253-1270.

9. Dick DE: Normal and leukemic human stem cells assayed in SCID mice. Semin Immunol 1996, 8:197-206.

10. Singh SK, Clarke ID, Terasaki M, Bonn VE, Hawkins C, Squire J, Dirks PB: Identification of a cancer stem cell in human brain tumors. Cancer Res 2003, 63:5821-5828.

11. Al-Haij M, Wicha MS, Benito-Hernandez A, Morrison SJ, Clarke MF: Prospective identification of tumorigenic breast cancer cells. Proc Natl Acad Sci USA 2003, 100:3983-3988.

12. Abraham BK, Fritz $P$, McClellan $M$, Hauptvogel $P$, Athelogou $M$, Brauch $\mathrm{H}$ : Prevalence of $\mathrm{CD} 44^{+} / \mathrm{CD} 24^{-/ \text {low }}$ cells in breast cancer may not be associated with clinical outcome but may favor distant metastasis. Clinical Cancer Res 2005, 11:11541159.

13. Chang CC, Sun W, Cruz A, Saitoh M, Tai MH, Trosko JE: A human breast epithelial cell type with stem cell characteristics as target cells for carcinogenesis. Radiat Res 2001, 155:201-207.

14. Sun W, Kang KS, Morita I, Trosko JE, Chang CC: High susceptibility of a human breast epithelial cell type with stem cell characteristics to telomerase activation and immortalization. Cancer Res 1999, 59:6118-6123.
15. Kang KS, Morita I, Cruz A, Jeon YJ, Trosko JE, Chang CC: Expression of estrogen receptors in a normal human breast epithelial cell type with luminal and stem cell characteristics and its neoplastically transformed cell lines. Carcinogenesis 1997, 18:251-257.

16. Chang CC: Normal adult breast stem cells as 'targets' for breast carcinogenesis implications for chemoprevention and chemotherapy. In Proceedings of the Era of Hope Dept. of Defense Breast Cancer Res Program Meeting, 8-11 June 2005, Philadelphia, PA. Fort Detrick, MD: Department of the US Army Medical Research and Materiel Command; 2005:256.

17. Kang KS, Sun W, Nomata K, Morita I, Cruz A, Liu CJ, Trosko JE, Chang CC: Involvement of tyrosine phosphorylation of p $185^{\mathrm{C}-e r b B} 2 / \mathrm{neu}$ in tumorigenicity induced by X-rays and the neu oncogene in human breast epithelial cells. Mol Carcinog 1998, 21:225-233.

18. Lee SW, Tomasetto C, Sager R: Positive selection of candidate tumor-suppressor genes by subtractive hybridization. Proc Natl Acad Sci USA 1991, 88:2825-2829.

19. Sager R, Anisowicz A, Neveu M, Liang P, Sotiropoulou G: Identification by differential display of alpha 6 integrin as a candidate tumor suppressor gene. FASEB J 1993, 7:964-970.

20. Zou Z, Anisowicz A, Hendrix MJ, Thor A, Neveu M, Sheng S, Rafidi K, Seftor E, Sager R: Maspin, a serpin with tumor-suppressing activity in human mammary epithelial cells. Science 1994, 263:526-529.

21. Weiss S, Reynolds BA, Vescovi AL, Morshead CM, Craig CG, van der Kooy D: Is there a neural stem cell in the mammalian forebrain? Trends Neurosci 1996, 19:387-393.

22. Wilson C, Dering J: Role of the ROR1 recceptor tyrosine kinase in ER-negative basal breast cancer. In Proceedings of the Era of Hope Dept. of Defense Breast Cancer Res Program Meeting, 8-11 June 2005, Philade/phia, PA. Fort Detrick, MD: Department of the US Army Medical Research and Materiel Command; 2005:25

23. Li $Y$, Welm B, Podsypanina $K$, Huang $S$, Chamorro $M$, Zhang $X$ Rowlands T, Egeblad M, Cowin P, Werb Z, et al.: Evidence that transgenes encoding components of the Wnt signaling pathway preferentially induce mammary cancers from progenitor cells. Proc Natl Acad Sci USA 2003, 100:15853-15858.

24. Ponti D, Costa A, Zaffaroni N, Pratesi G, Petrangolini G, Coradini $D$, Pilotti S, Pierotti MA, Daidone MG: Isolation and in vitro propagation of tumorigenic breast cancer cells with stem/ progenitor cell properties. Cancer Res 2005, 65:5506-5511.

25. Hope KJ, Jin L, Dick JE: Acute myeloid leukemia originates from a hierarchy of leukemic stem cell classes that differ in self-renewal capacity. Nat Immuno/ 2004, 5:738-743. 